\title{
LITERATURE REVIEW: PSYCHOSOCIAL CARE PERAWAT DI RUANG RAWAT INAP RUMAH SAKIT
}

\author{
Elasari, Yunina ${ }^{1}$, Hasanah, Annida ${ }^{2}$, Alawiyah, Tuti ${ }^{3}$ \\ ${ }^{1,2,3}$ Fakultas Kesehatan Universitas Sari Mulia \\ Email: ayiedeh@gmail.com
}

\begin{abstract}
Psychosocial care is an important component in providing patient-focused care, which aims to improve psychological and emotional well-being such as self-esteem, disease adjustment, communication, social functioning and interpersonal relationships. This study identified definitions, barriers and efforts to improve nurses' psychosocial care in inpatient wards based on empirical studies in the last five years. This study used a literature review study approach by using several sources selected based on the criteria set by the researcher. From 10 journals that conducted a literature review, it was found that the definition of psychosocial care is psychological, social and spiritual care through therapeutic communication and a holistic approach. Barriers to psychosocial care were lack of time, language barriers, lack of knowledge and skills, lack of family involvement and excessive documentation. Efforts to improve psychosocial care could be like training, professional team support and involving families in care. In conclusion, Psychosocial care as part of a holistic care has its own challenges. Strong efforts are needed to overcome obstacles and improve nurses' psychosocial care by means of psychosocial care training, interprofessional collaboration and involving families in care.
\end{abstract}

Keywords: Nurse, Psychosocial Care, Inpatient Care

\begin{abstract}
Abstrak
Psychosocial care merupakan komponen yang penting dalam memberikan perawatan dengan berfokus kepada pasien yang bertujuan untuk meningkatkan kesejahteraan psikologis dan emosional seperti harga diri, penyesuaian penyakit, komunikasi, fungsi sosial dan hubungan interpersonal. Penelitian ini bertujuan untuk mengidentifikasi definisi, hambatan dan upaya dalam meningkatkan psychosocial care perawat di ruang rawat inap berdasarkan studi empiris lima tahun terakhir. Penelitian ini menggunakan pendekatan study literature review dengan menggunakan beberapa sumber yang dipilih berdasarkan kriteria yang telah ditetapkan peneliti. Dari 10 jurnal yang dilakukan kajian literature didapatkan definisi psychosocial care adalah perawatan psikologis, sosial dan spiritual melalui komunikasi terapeutik dan pendekatan holistik. Hambatan psychosocial care: kurangnya waktu, hambatan bahasa, kurang pengetahuan dan keterampilan, kurang keterlibatan keluarga serta dokumentasi berlebihan. Upaya untuk meningkatkan psychosocial care: pelatihan, dukungan tim profesional dan melibatkan keluarga dalam perawatan. Psychosocial care adalah perawatan yang holistik dan memiliki tantangan tersendiri bagi perawat dalam mengaplikasikannya sehingga perlunya upaya untuk mengatasi hambatan dan meningkatkan psychosocial care perawat dengan cara pelatihan psychosocial care, kolaborasi interprofesional dan melibatkan keluarga dalam perawatan.
\end{abstract}

Kata Kunci: Perawat, Psychosocial Care, Rawat Inap

\section{Pendahuluan}

Aspek psikososial merupakan salah satu komponen penting dalam keperawatan komprehensif. Para ahli teori keperawatan seperti Betty Neuman dan Jean Watson menekankan bahwa selain perawatan fisik, juga harus memperhatikan kebutuhan psikologis, sosial dan spiritual pasien. Pada awalnya pengobatan medis untuk menyembuhkan penyakit dipercaya sangat efektif dalam penyembuhan penyakit pasien sehingga kebutuhan psikososial tidak dianggap penting dalam bidang kesehatan. Namun, saat ini banyak penelitian terbaru yang menyatakan bahwa hati yang bahagia dan pikiran yang sehat sangat penting untuk mencegah berbagai penyakit (Arulappan, 2016).

Ketika pasien dirawat di rumah sakit dalam waktu yang lama, pasien seringkali menerima obat dan berbagai macam intervensi. Pasien cenderung mengembangkan perasaan putus asa, kelemahan, penurunan kualitas hidup, isolasi, perubahan dalam hubungan sosial, perubahan citra tubuh, kecemasan dan depresi. Masalah yang dihadapi oleh pasien ini perlu diberikan intervensi dan perawatan yang tepat untuk meningkatkan segala aspek kesehatan 
salah satunya adalah kesejahteraan psikosoial (Mersin et al, 2018).

Kesejahteraan psikososial yang baik dapat meningkatkan hasil kesehatan pasien dan mengurangi kecemasan, stress dan durasi rawat inap sehingga dapat meningkatkan kualitas hidup (Legg, 2011; Chen et al, 2017). Pasien perlu diberikan pelayanan keperawatan yang memuaskan dan sesuai dengan kebutuhan pasien saat dirawat agar mencapai pelayanan kesehatan yang optimal, termasuk perawatan psikososial (Yanto \& Setyawati, 2017).

Psychosocial care atau perawatan psikososial merupakan komponen yang penting dalam memberikan perawatan dengan berfokus kepada pasien yang bertujuan untuk meningkatkan kesejahteraan psikologis dan emosional seperti harga diri, penyesuaian penyakit, komunikasi, fungsi sosial dan hubungan interpersonal. Psychosocial care tidak hanya berfokus pada kesejahteraan emosional tetapi juga hubungan keluarga, komunitas, budaya dan spiritual (Fan, 2017).

Perawat adalah tenaga kesehatan yang terbanyak di rumah sakit yaitu sekitar $40 \%$. Perawat merupakan tenaga kesehatan dengan jam kerja yang berkesinambungan selama 24 jam dalam memberikan pelayanan asuhan keperawatan kepada pasien sehingga, ujung tombak pelayanan kesehatan di rumah sakit berada di tangan perawat (Kementerian Kesehatan RI, 2017; Silalahi dkk, 2019).

Perawat sangat berperan penting untuk memberikan psychosocial care kepada pasien. Hal ini dapat direalisasikan dalam perawatan dasar melalui empati, memberikan dukungan, memberikan informasi, mendengarkan dan menemani pasien. Perawat harus mampu menghormati nilai- nilai pasien, memberdayakan, membantu pasien menemukan makna, meningkatkan hubungan antara pasien dan keluarga dan menjaga integritas mereka sendiri (Fan, 2017).

Perawat menganggap bahwa perawatan psikososial berbeda dengan perawatan fisik yang memiliki cara standar sehingga perawat tidak tahu bagaimana memberikan psychosocial care kepada pasien seperti berbicara atau bertanya maupun menjawab pertanyaan dan merespon dengan tepat yang membuat perawat memilih menghindar untuk memberikan psychosocial care (Fan, 2017).
Kemampuan yang dimiliki perawat dalam memberikan psychosocial care sangat penting untuk mengidentifikasi dan mengelola masalah pasien secara efektif agar meningkatkan proses pemulihan pasien serta mengurangi frustasi yang dialami oleh perawat. Namun, untuk menentukan dan memenuhi kebutuhan psikososial pasien, perawat menghadapi berbagai hambatan yang dirasakan. Perawat sering merasa tidak siap untuk menghadapi berbagai reaksi, tuntutan, dan masalah kejiwaan pasien sambil berusaha memberikan perawatan kebutuhan fisiologis pasien (Mersin $e t$ $a l, 2018)$.

Berdasarkan penelitian yang dilakukan Aksoy et al (2019) didapatkan bahwa perawat mengalami kesulitan dalam memberikan psychosocial care kepada pasien. Perawat merasa memiliki pengetahuan yang kurang terkait psychosocial care dan mereka merasa tidak memiliki waktu yang cukup untuk memberikan perawatan psychosocial care karena beban kerja yang berat serta jumlah pasien yang tinggi.

Hambatan yang dialami oleh perawat dalam memberikan psychosocial care tersebut berdampak pada keletihan yang dirasakan oleh perawat. Keletihan yang dialami perawat memiliki konsekuensi serius bagi perawat, rumah sakit dan pasien. Perawat yang tidak memiliki keterampilan dalam psychosocial care dapat mengakibatkan stres bagi perawat. Selain itu, ketidakmampuan perawat dalam menghadapi hambatan untuk memberikan psychosocial care akan berdampak pada kebutuhan psikososial pasien yang tidak terpenuhi sehingga mengakibatkan ketidakpuasan pasien terhadap kualitas layanan dan meningkatnya tekanan psikososial pasien maupun keluarga pasien mencakup masalah emosional, kognitif, sosial dan fungsional (Weis, 2015). Pelatihan dan pengawasan keterampilan psikososial dapat menjadi cara untuk meningkatkan kepuasan kerja dan mengurangi keletihan diantara perawat (Mcmillan, 2016).

Berdasarkan uraian tersebut didapatkan bahwa perawat belum memahami dengan baik pelaksanaan psychosocial care, mengalami hambatan dalam melaksanakan perawatan tersebut, dan perlunya upaya untuk meningkatkan psychosocial care sehingga peneliti akan mengidentifikasi definisi, hambatan dan, upaya dalam meningkatkan psychosocial care perawat di ruang rawat inap berdasarkan studi empiris lima tahun terakhir. 


\section{Metode Penelitian}

Penelitian ini menggunakan pendekatan studi literature review yang berfokus pada evaluasi beberapa hasil penelitian sebelumnya yang berkaitan dengan topik atau variabel penelitian.

Tabel 1.1 Strategi Pencarian Literatur

\begin{tabular}{lll}
\hline Data Based & Temuan & $\begin{array}{l}\text { Literatur } \\
\text { Terpilih }\end{array}$ \\
\hline Google Scholar & 22 & 3 \\
PubMed & 127 & 5 \\
Science Direct & 223 & 2 \\
JUMLAH & 372 & 10 \\
\hline
\end{tabular}

Kriteria Literatur

Kriteria inklusi pada penelitian ini yaitu sumber literature memiliki populasi penelitian yaitu perawat ruang rawat inap, menjelaskan tentang psychosocial care perawat di ruang rawat inap rumah sakit, Metode penelitian meliputi kualitatif, kuantitatif, crosssectional, mix methods. Tahun publikasi sumber literature yang diambil yaitu 5 tahun terakhir antara tahun 2015 sampai dengan 2020 dan menggunakan bahasa Inggris atau Indonesia.

Diagram 1.1 Tahapan Literature Review

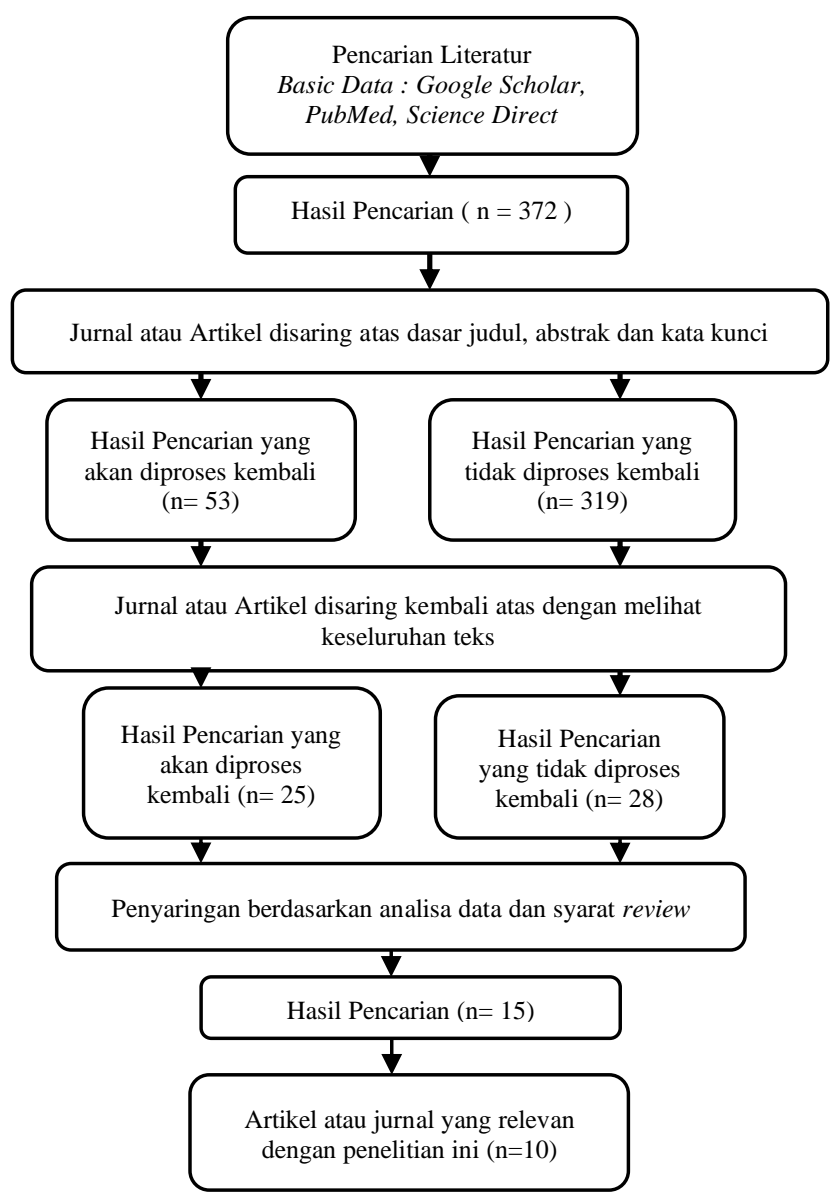

\section{Hasil Penelitian}

Hasil pencarian melalui review sebanyak 372 jurnal lalu diidentifikasi menjadi 53 jurnal, lalu dilakukan skrining kembali menjadi 25 jurnal, dan diakukan uji kelayakan menjadi 10 jurnal. Kesepuluh jurnal tersebut adalah jurnal yang digunakan dalam literature review ini. Hasil dalam penelitian ini didapatkan definisi psychosocial care, hambatan psychosocial care (kurangnya waktu, kurang pengetahuan dan keterampilan, hambatan bahasa, dokumentasi yang berlebihan serta kurangnya keterlibatan keluarga) dan upaya dalam meningkatkan psychosocial care (pelatihan, perawatan interprofesional dan melibatkan keluarga dalam perawatan).

\section{Pembahasan}

1. Definisi Psychosocial Care

Psychosocial care merupakan perawatan psikologis, sosial dan spiritual melalui komunikasi terapeutik dan pendekatan holistik (Chen et al, 2017). Pendekatan holistik tersebut juga sejalan dengan teori Kenny \& Allenby (2013) yang mendefinisikan bahwa perawatan psikososial dilakukan dengan pendekatan secara holistik kepada pasien, sehingga sangat penting bagi perawat untuk melakukan perawatan psikologis dalam proses asuhan keperawatan diruang rawat inap.

Hasil temuan literatur menurut Guner et al (2018), mengungkapkan bahwa perawatan psikososial sebagai proses yang melibatkan penghargaan seperti kepuasan, pertumbuhan pribadi dan kelelahan. Dapat disimpulkan bahwa psychosocial care merupakan asuhan keperawatan yang diberikan oleh perawat kepada pasien dengan pendekatan holistik, tidak hanya memperhatikan perawatan fisik tetapi memperhatikan perawatan psikososial yang dibutuhkan oleh pasien yang menghasilkan kepuasan, perkembangan diri, dan kelelahan dalam prosesnya.

2. Hambatan Psychosocial Care

Studi literatur menurut Chen et al (2017), Guner et al (2018), Pehlivian et al (2016), menunjukkan bahwa kurangnya waktu adalah salah satu hal yang dapat menghambat perawat dalam memberikan psychosocial care kepada pasien. Perawat merasa tidak memiliki waktu yang cukup untuk meluangkan waktu selain memberikan perawatan biologis dikarenakan 
di bangsal rawat inap perawat selalu sibuk dengan pekerjaan rutinnya serta jumlah pasien yang dirawat cukup banyak dengan durasi perawatan yang cukup lama.

Hasil temuan ini serupa dengan penelitian sebelumnya Balboni et al (2014), menemukan bahwa perawat merasa kurangnya waktu dalam memberikan psychosocial care pada pasien. Perawat ruang rawat inap memiliki beban kerja yang besar dikarenakan jumlah pasien yang banyak dan tuntutan kerja yang wajib diselesaikan dengan tepat waktu sebelum pergantian shift membuat perawat tidak memiliki waktu yang cukup untuk memberikan perawatan psikososial kepada pasien rawat inap. Akhirnya, perawat lebih mengutamakan perawatan fisik terlebih dahulu dan mengesampingkan perawatan psikososial.

Hasil literatur lain didapatkan bahwa kurangnya pengetahuan dan keterampilan perawat dalam memberikan psychosocial care merupakan salah satu hambatan (Fan et al, 2017). Hasil temuan literatur terkait hambatan kurang pengetahuan mirip dengan studi yang mengungkapkan bahwa perawat merasakan kurangnya pelatihan tentang cara mendekati masalah emosional pasien. Perawat merasa takut mengatakan atau melakukan sesuatu yang salah dan merasa kurang tentang pengetahuan dan keterampilan komunikasi mereka (Zamanzadeh et al, 2014). Kurang pengetahuan dan keterampilan perawat adalah stressor dan hambatan bagi perawat dalam menyediakan perawatan psikososial. Ketidaktahuan perawat akan kebutuhan psikososial pasien menghalangi perawat untuk memberikan perawatan secara holistik sehingga kebutuhan psikososial pasien tidak terpenuhi secara optimal.

Dari hasil literatur Chen et al (2017), bahasa merupakan salah satu hambatan bagi perawat untuk memberikan psychosocial care. Hambatan bahasa ini menjadi halangan bagi perawat untuk berkomunikasi dengan baik kepada pasien. Perawat mengungkapkan bahwa hambatan bahasa ini sering muncul ketika sedang berhadapan dengan pasien lansia yang berbicara dengan dialek lokal atau bahasa daerah yang tidak diketahui oleh perawat.

Hasil temuan ini sejalan dengan penelitian lain (Legg, 2011; Taylor, Nicolle, Maguire, 2013) bahwa perawat merasa memiliki masalah dalam berkomunikasi dengan pasien terutama pada pasien yang lanjut usia dikarenakan pasien ini sering berkomunikasi dalam dialek lokal. Bahasa yang tidak dimengerti oleh perawat dapat menghambat komunikasi perawat dengan pasien, padahal komunikasi terapeutik merupakan aspek yang sangat penting agar perawat mampu memenuhi kebutuhan dan perawatan psikososial pasien.

Menurut chen et al (2017) dokumentasi yang berlebihan adalah hambatan lain yang diungkapkan oleh perawat dalam memberikan psychosocial care kepada pasien. Sebagian besar perawat mengatakan mereka sibuk dengan tugas persyaratan dokumentasi dan tidak memiliki waktu yang memadai untuk berinteraksi dengan pasien. Temuan literatur tersebut didukung oleh penelitian sebelumnya yang menemukan bahwa dokumentasi pasien yang berfokus pada kebutuhan medis lebih diutamakan daripada kebutuhan psikososial pasien sehingga mencegah penyediaan perawatan psikososial (Kenny \& Allenby, 2013).

Temuan literatur menurut Chen et al (2017) mengungkapkan bahwa perawat merasa kurangnya keterlibatan keluarga secara langsung dalam perawatan pasien menjadi hambatan bagi perawat dalam memberikan psychosocial care mengingat keterbatasan waktu yang tersedia. Selain itu, kurangnya kemandirian pasien dan keluarga pasien dalam memberikan perawatan dasar seperti memandikan atau menyuapi pasien dapat mencegah perawat untuk memberikan perawatan psikososial. Hal ini mengakibatkan perawat perlu menghabiskan lebih banyak waktu untuk menyediakan perawatan dasar dan memiliki sedikit waktu yang tersedia untuk memberikan perawatan psikososial kepada pasien mereka.

Hasil temuan literatur tersebut didukung dengan penelitian sebelumnya di Singapura oleh Tay et al (2012) mengungkapkan bahwa pasien dan anggota keluarga mengharapkan perawat untuk memberikan perawatan dasar.

3. Upaya Meningkatkan Psychosocial Care Berdasarkan temuan literatur tekait upaya untuk mengatasi hambatan psychosocial care menurut Chan et al (2019) adalah dengan mentransfer pengetahuan melalui bimbingan dari perawat senior ke perawat junior secara 
berkelanjutan dan diringi dengan pelatihan terkait keterampilan psychosocial care dan komunikasi. Temuan literatur tersebut sejalan dengan penelitian Stoop et al (2018), melalui pelatihan profesional tambahan yang berfokus bagaimana membahas dan merawat masalah emosional serta bagaimana memberikan perawatan terpadu untuk masalah psikososial pada pasien dapat meningkatkan kemampuan perawat dalam memberikan psychosocial care.

Hasil temuan literatur menurut Fan et al (2017), perawat memerlukan kerja tim multidisplin sehingga perawatan kesehatan yang berbeda harus bekerjasama dan berkomunikasi dengan baik. Dukungan khusus dari profesional kesehatan dapat mengatasi kesulitan dan memberikan dukungan kepada perawat.

Selain itu penelitian sebelumnya yang dilakukan oleh Pape et al (2013) bahwa perawatan interprofesional sebagai aspek penting dari perawatan psikososial dan bahwa perawatan utama terdiri dari dua bagian: kolaborasi dengan profesional kesehatan dan keterlibatan perawatan multidisiplin. Hal ini menunjukkan bahwa perawatan interprofesional membantu mengurangi kegagalan komunikasi dan hambatan perawatan psikososial.

Temuan literatur menurut Stuckey et al (2015) bahwa salah satu upaya untuk mengatasi hambatan psychosocial care adalah dengan cara melibatkan keluarga dalam segala perawatan yang dijalani oleh pasien. Temuan ini sejalan dengan studi sebelumnya Torenholt et al (2014) yang mengatakan bahwa perbaikan besar diperlukan dalam penyediaan perawatan kesehatan khususnya menyediakan sumber daya untuk perawatan psikologis sepeti mendengarkan pasien, melibatkan keluarga dan memotivasi pasien.

\section{Kesimpulan}

Psychosocial care merupakan pemberian pelayanan keperawatan yang holistik oleh perawat dengan pendekatan budaya, psikologis dan spiritual melalui komunikasi terapeutik yang bagus sehingga tercapainya kepuasan pribadi perawat dalam bekerja. Psychosocial care yang efektif dapat meningkatkan hasil kesehatan yang optimal dengan cara mendengarkan, memberikan dukungan dan memberikan informasi serta saran yang mendalam secara terapeutik.

Perawat seringkali mengalami hambatan dan tantangan dalam memberikan psychosocial care kepada pasien. Kurangnya waktu, kurang pengetahuan dan keterampilan, hambatan bahasa, dokumentasi yang berlebihan serta kurangnya keterlibatan keluarga merupakan hambatan utama perawat dalam memberikan psychosocial care.

Pelatihan, perawatan interprofesional, dan melibatkan keluarga dalam perawatan dapat menjadi cara untuk meningkatkan kepuasan kerja dan mengurangi hambatan diantara perawat dalam memberikan psychosocial care.

\section{Acknowledgment}

Peneliti mengucapkan terimakasih sebesarbesarnya kepada Rektorat dan Dekan Fakultas Kesehatan Universitas Sari Mulia Banjarmasin yang telah memberikan dukungan dan kesempatan dalam melakukan penelitian ini.

\section{Daftar Pustaka}

Aksoy A. 2019. Nursing Students Percepective on Psychosocial Care and Their Knowledge Levels. International Journal of Caring Sciences. 12(2): 1034-1040. Tersedia pada: https://www.internationaljournalofcaringsci ences.org/docs/48_kilic_original_122.pdf. [Diunduh 12 Mei 2020]

Arulappan J. 2016. Psycho Social Nursing Care for Better Patient Outcome. Nursing \& Care Open Access Journal. 1(1): 10-11. Tersedia pada:

https://medcraveonline.com/NCOAJ/NCO AJ-01-00004.pdf. [Diunduh 17 Desember 2019]

Balboni MJ, Sullivan A, Enzinger AC, Zollfrank A, Vanderweele TJ, Balboni TAB. 2014. Nurse and Physician Barriers to Spiritual Care Provison at the End of Life. Journal of Pain and Symptom Management. 48(3): 111. Tersedia pada: https://www.ncbi.nlm.nih.gov/pmc/articles/ PMC4569089/pdf/nihms720899.pdf.

[Diunduh 12 Juli 2020]

Chan EA, Tsang PL, Ching SSY, Wong FY, Lam W. 2019. Nurses Perspective on Their 
Communication With Patient in Busy Oncology Wards: A Qualitative Study. PLOS ONE. 1-21. Tersedia Pada: https://www.ncbi.nlm.nih.gov/pmc/articles/ PMC6812861/pdf/pone.0224178.pdf. [Diakses 17 Desember 2019]

Chen CS, Chan SW, Chan MF, Yap SF. 2017. Nurses Perceptions of Psychosocial Care and Barriers to its Provision: A Qualitative. The Journal of Nursing Research. 25(6): 18. Tersedia Pada: https://journals.lww.com/jnrtwna/Fulltext/2 017/12000/Nurses Perceptions ofPsychos ocial_Care_and.3.aspx. [Diakses 17 Desember 2019]

Fan SY, Lin IM, Hsich JG, Chang CJ. 2017. Psychosocial Care Provided by Physician and Nurse in Palliative Care. A mixed Methods Study: Journal of Pain and Symptom Management. 53(2): 216-223. Tersedia Pada: https://www.jpsmjournal.com/article/S0885 -3924(16)30492-4/pdf. [Diunduh 17 Desember 2019]

Guner P, Hicdurmaz D, Yildirim NK, Inci F. 2018. Psychosocial Care From the Perspective of Nurses Working In Oncology: A Qualitative Study. European Journal of Oncology Nursing. 34(2018):68-75. Tersedia Pada: https://www.ejoncologynursing.com/article/ S1462-3889(18)30051-6/fulltext. [Diunduh 25 Mei 2020]

Kenny A and Alennby A. 2013. Barriers to Nurses Providing Psychosocial Care in the Australian Rural Context. Nursing and Health Sciences. 15(2): 194-200. Tersedia Pada:

https://onlinelibrary.wiley.com/doi/epdf/10. 1111/nhs.12014. [Diakses 12 Juli 2020]

Mcmillan K, Butow P, Turner J, Yates P, White K, Lambert S, Stephens M, Lawsin C. 2016. Burnout and the Provision of Psychosocial Care Amongst Australian Cancer Nurses. European Journal of Oncology Nursing. 22(2016): 37-45. Tersedia Pada: https://www.ejoncologynursing.com/article/ S1462-3889(16)30014-X/fulltext. [Diunduh 5 Juni 2020]

Mersin S, Demiralp M, Oksuz E. 2019. Addressing the Psychosocial Needs of Patient:
Challenge for Nursing Students. Perspectives Psychiatric Care. 55(2): 1-8. Tersedia Pada: https://onlinelibrary.wiley.com/doi/full/10.1 111/ppc.12365. [Diunduh 5 Juni 2020]

Pape B, Thiessen PS, Jakobsen F, Hansen TB. 2013. Interprofessional collaboration may pay off: introducing a collaborative approach in an orthopaedic ward. Journal of Interprofessional Care. 27(6): 496-500. Tersedia Pada: https://www.tandfonline.com/doi/full/10.31 09/13561820.2013.808611. [Diakses 1 Juli 2020]

Pehlivan T, Kucuk L. 2016. Skills of Oncology Nurses in Diagnosing the Psychosocial Needs of The Patients. International Journal of Caring Sciences. 9(2): 658-668. Tersedia Pada:

https://www.internationaljournalofcaringsci ences.org/docs/27Kucuckoriginal91.pdf. [Diunduh 15 Juni 2020]

Silalahi J, Fitriani AD, Megawati. 2019. Analisis Mutu Pelayanan Perawat Terhadap Kepuasan Pasien Rawat Inap Kelas III di Rumah Sakit Advent Medan. Jurnal Kesehatan Perintis. 6(1): 21-29. Tersedia Pada:

https://jurnal.stikesperintis.ac.id/index.php/ JKP/article/download/165/139/. [Diunduh 17 Januari 2020]

Stoop C, Pouwer F, Pop V, Outsten BD, Nefs G. 2019. Psychosocial health care needs of people with type 2 diabetes in primary care: Views of patients and health care providers. Journal Advanced Nursing. 75:1702-1712. Tersedia Pada: https://onlinelibrary.wiley.com/doi/df/10.11 11/jan.1399. [Diunduh 20 Juni 2020]

Stuckey HL, Vallis M, Burns KK, Jensen CBM, Reading JM, Kalra S, Wens J, Kokoszka A, Skovlund SE, Peyrot M. 2015. I Do My Best To Listen to Patients": Qualitative Insights Into DAWN2 (Diabetes Psychosocial Care From the Perspective of Health Care Professionals in the Second Diabetes Attitudes, Wishes and Needs Study). Clinical Therapeutics. 37(9): 1986-1998. Tersedia Pada: https://www.clinicaltherapeutics.com/article 
/S0149-2918(15)00873-5/fulltext. [Diunduh 20 Juni 2020]

Tay LH, Ang E, Hegney D. 2012. Nurses Perceptions of the Barriers in Effective Communication With Inpatient Cancer Adults in Singapore. Journal of Clinical Nursing. $\quad$ 21(17-18). Tersedia Pada: https://onlinelibrary.wiley.com/doi/full/10.1 111/j.1365-2702.2011.03977. [Diakses 22 Juni 2020]

Taylor SP, Nicolle C, Maguire C. 2013. CrossCultural Communication Barriers in Health Care. Nursing Standard. 27(31): 35- 43. Tersedia Pada:https://www.deepdyve.com/lp/royalcollege-of-nursing-ren/cross-culturalcommunication-barriers-in-health-careyvrpHy3wMo. [Diakses 10 Juli 2020]

Torenholt R, Schwennesen N, Willaing I. 2013. Lost in Translation- The Role of Family in Intervention Among Adults With Diabetes: a Systematic Review. Diabetic Medicine. 31(1). Tersedia Pada:https://onlinelibrary.w0iley.com/doi/a bs/10.1111/dme.12290. [Diunduh 15 Juni Juli 2020]

Weis J. 2015. Psychosocial Care for Cancer Patients. Breast Care. 10: 84-86. Tersedia Pada:

https://www.ncbi.nlm.nih.gov/pmc/articles/ PMC4463789/pdf/brc-0010-0084.pdf.

[Diunduh 20 April 2020]

Yanto A and Setyawati DS. 2017. Psychosocial Needs of Type 2 Diabetes Melitus Patient in Semarang City. Health Notion. 1(3): 189191.

Tersedia Pada:http://heanoti.com/index.php/hn/articl e/download/hn1307/38. [Diunduh 8 Januari 2020]

Zamanzadeh V, Rassouli M, Abbaszadeh A, Nikanfar A, Alavi-Majd H, Ghahramanian A. 2014. Factors influencing communication between the patients with cancer and their nurses in oncology wards. Indian Journal Palliative Care. 20(1): 12-20. Tersedia Pada:http://www.jpalliativecare.com/article. asp?issn=09731075; year=2014; volume $=20$; issue $=1 ;$ spage $=12$; epage $=20$; aulast $=$ Zaman zadeh. [Diakses 10 Juli 2020]. 